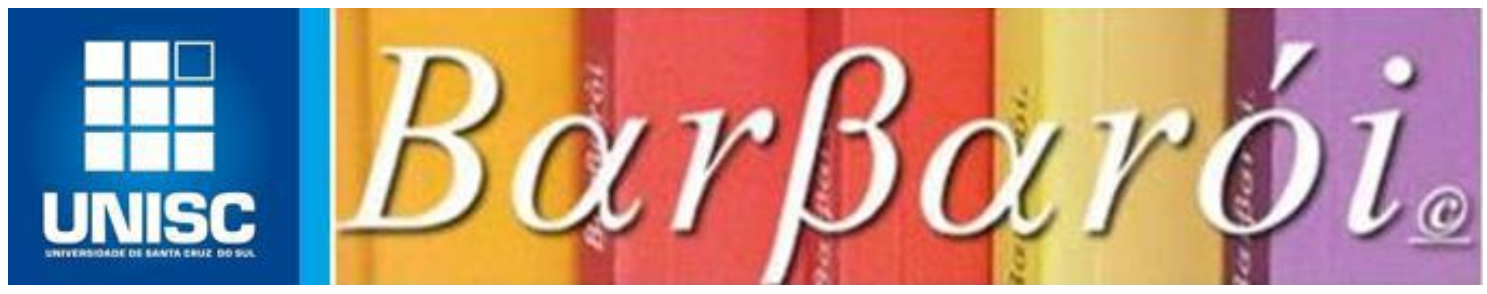

\title{
POLÍTICA E PROTESTO NO BRASIL RECENTE: AS MANIFESTAÇÕES DE JUNHO DE 2013 NAS RUAS DE SÃO PAULO
}

\section{DOI: http://dx.doi.org/10.17058/barbaroi.v1i53.11222}

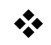 \\ José Carlos Martines Belieiro Júnior \\ Universidade Federal de Santa Maria - UFSM - Brasil \\ Ezer Azael Moreira Lopes \\ Universidade Federal de Santa Maria - UFSM - Brasil
}

\section{Resumo}

O objetivo do presente artigo é analisar os movimentos de protesto ocorridos em junho de 2013 na cidade de São Paulo. Como se sabe, esses movimentos ou jornadas de junho, chamaram a atenção de analistas e cientistas sociais da vida brasileira por sua complexidade, tamanho e variedade de demandas apresentadas. De outro lado, a dimensão que assumiram os protestos de junho, que a partir da capital paulista, tomaram conta das ruas no Brasil todo, também simbolizaram na prática o início de um verdadeiro ciclo de protestos na sociedade brasileira contemporânea, com fortes impactos na esfera política e nas formas de organização e mobilização social. O trabalho procura entender os movimentos de junho de 2013 a partir de sua dimensão ideológica, tentando tornar possível enquadrar os acontecimentos de junho sob uma perspectiva política de direita ou de esquerda.

Palavras-chave: movimentos sociais; junho de 2013; política e protesto.

\section{Introdução}

O objetivo do presente artigo é fazer uma breve análise das manifestações de rua ocorridas na cidade de São Paulo no mês de junho de 2013. Como se sabe, aqueles movimentos de protesto iniciados na capital paulista espalharam-se por todo o país, apresentando conteúdo político-ideológico complexo, demandas e pautas diversas e uma composição social heterogênea. Nesse sentido, as manifestações de junho de 2013 na capital paulista representam um bom modelo para a análise daqueles movimentos que vieram a assumir uma verdadeira dimensão nacional. As manifestações que ocorreram durante o mês de junho de 2013 apresentaram-se como um fenômeno social quase inédito no Brasil contemporâneo, devido às suas proporções e seu caráter plural e multifacetado. Por essa razão, logo de sua ocorrência os 
protestos de junho tornaram-se objeto de análise e intensos debates, chamando a atenção de especialistas na academia, mas também na mídia e na opinião pública em geral, disseminando opiniões, pontos de vista e suscitando interpretações as mais diversas sobre os movimentos de 2013. Segundo a socióloga Ângela Alonso (2017, p. 49), desde o ciclo de protestos que tem início naquele mês, concorrem vários interpretes e autores no campo acadêmico. Entre estes, pode-se agrupar três abordagens principais sobre os movimentos de 2013. São as seguintes abordagens nas palavras de Alonso (2017, p. 49), "conforme ênfase em causas, atores ou no processo de mobilização".

A partir da abordagem que enfatiza as causas dos movimentos de 2013, a socióloga da USP destaca os trabalhos de Singer (2013) e Marcos Nobre (2013). Os dois autores desafiaram a condição de escreverem seus trabalhos de interpretação no contexto imediatamente posterior aos eventos. Ambos identificam as causas que impulsionaram os protestos de 2013 na conjuntura política, econômica e social do Brasil dos últimos anos do governo Dilma Rousseff (2010-2014). De outro lado, a abordagem centrada nos atores dos protestos, Alonso destaca os trabalhos de Losekann (2013), Ortellado et al. (2013), Malini et al. (2014), Feres Jr; Miguel; Barbarela (2014) e Bucci (2016). Nestes autores, Alonso argumenta que a ênfase da análise recai no papel dos diferentes atores durante os protestos de junho de 2013. Assim, são ressaltados os papéis desempenhados pela mídia tradicional nos movimentos (Feres Jr.; Miguel; Barbarela, 2014); na análise da presença relevante das mídias sociais (twitter) na divulgação e mobilização para os protestos (Malini et al., 2014) e, ainda, nos grupos organizados que se mobilizaram em protestos de nas ruas naquele momento (Losekan, 2013; Ortellado et al., 2013; Bucci, 2016).

Já no terceiro grupo de abordagens sobre junho de 2013, na qual a própria autora se filia (Alonso; Mische, 2017), o destaque da análise se concentra nos processos de mobilização e repertório de protesto dos grupos e indivíduos que participaram dos movimentos em São Paulo. Esta forma de interpretação se vincula no paradigma norte-americano de análise dos movimentos sociais, conforme analisou Gohn (1999). A socióloga articula os conceitos de Charles Tilly (2008) e Sidney Tarrow (1999) para abordar aquilo que os autores chamam ciclo de protestos. Encontram-se neste grupo de intérpretes, Bringel e Domingues (2013), Silva (2014) e Luciana Tatagiba (2014).

Para as finalidades deste artigo, parte-se destas interpretações destacadas por Alonso (2017) e adiciona-se ainda duas autoras que não foram mencionadas em artigo recente, mas que igualmente propõe análises sobre as manifestações de junho de 2013. As autoras são referências obrigatórias na análise dos movimentos sociais na sociologia brasileira: Ilse Scherer-Warren Barbarói, Santa Cruz do Sul, n.53, p.<01-25>,jan./jun. 2019 
(2014) e Maria da Gloria Gohn (2014a; 2015b). A primeira autora propõe uma interpretação das manifestações ideológicas e culturais dos grupos presentes nos protestos recentes no país e suas ligações às tradições herdadas de movimentos anteriores no Brasil. Já Gohn destaca o caráter "novo" dos protestos de junho de 2013, reforçado pela presença ativa das mídias sociais alternativas, na rapidez da circulação da informação e da convocação para os protestos, bem como suas semelhanças com outras manifestações difundidas pelo mundo no início do século XXI. A autora pontua as diferenças dos movimentos de 2013 em relação à outras formas e interpretações dos movimentos sociais clássicos. Este fenômeno novo ela acaba denominando de "novíssimos movimentos sociais dos indignados das praças, ruas e avenidas" (2015, p. 44). Acredita-se que o conjunto dessas interpretações representam as principais análises do fenômeno do junho de 2013 no Brasil.

$\mathrm{O}$ artigo procura contribuir com o debate acadêmico sobre as manifestações de junho de 2013 na perspectiva de analisar as diferentes e complexas dimensões ideológicas dos movimentos, buscando demonstrar como se configurou a díade direita-esquerda durante os protestos de junho de 2013 em São Paulo. A questão central do trabalho é responder como apareceram as ideologias de esquerda e direita durante as manifestações, se uma ou outra orientação prevaleceu nos movimentos e em quais condições. O artigo se concentra nos protestos da cidade de São Paulo/SP como um objeto especial de interpretação das manifestações que vieram depois tomar conta das ruas no Brasil contemporâneo.

$\mathrm{O}$ argumento principal deste trabalho é que os protestos se iniciaram por um movimento social organizado e orientado por uma ideologia de esquerda - o Movimento Passe Livre, com uma pauta específica, podendo ser enquadrada dentro do espectro das ideias de esquerda - a queda no preços das tarifas do transporte público em São Paulo ${ }^{1}$. Com o decorrer do mês, os movimentos contra o aumento da passagem se massificam e o perfil dos protestos torna-se heterogêneo e fragmentado, não sendo mais possível perceber a unificação em torno de uma pauta ou de um grupo social. Como tentativa de compreensão, o artigo mobiliza o conceito de hegemonia em Gramsci (1999) e Laclau e Mouffe (1985), referenciais importantes na tradição de pensamento social e político de inspiração marxista. A partir desse uso conceitual, pretendese analisar a fragmentação e a heterogeneização dos protestos de junho de 2013, na perspectiva da disputa de hegemonia dos grupos e das ideias de esquerda e direita, tornando os protestos de

\footnotetext{
${ }^{1}$ Vale lembrar também que a pauta histórica do Movimento Passe Livre (MPL), é a taxa zero nas tarifas de transporte público. (Gohn, 2015).
}

Barbarói, Santa Cruz do Sul, n.53, p.<01-25>,jan./jun. 2019 
2013 difusos e fragmentados no momento em que estes alcançam o caráter de manifestação de massa.

Desse modo, além das referências à utilização do conceito de hegemonia, o artigo propõe a retomada do conceito de direita-esquerda enquanto díade válida para se pensar a realidade social e política das manifestações de junho de 2013. Na seção seguinte, o trabalho pretende apresentar uma narrativa dos atos do mês de junho de 2013 nas ruas da cidade de São Paulo, acompanhados através da mídia impressa Folha de São Paulo. Nossa preocupação é encontrar elementos suficientes que possam sustentar a hipótese do encontro das ideologias de direita e esquerda no interior dos protestos. Associado a questão das ideologias políticas, o artigo debate e opera o conceito de hegemonia, referência importante nas análises sobre os protestos de 2013, principalmente no momento de massificação e fragmentação das manifestações. $\mathrm{O}$ artigo procura levantar uma hipótese sobre os movimentos de protesto em São Paulo, e assim contribuir para o rico debate sobre as manifestações de junho de 2013, mas ao mesmo tempo ajudar a pensar os dilemas e tensões da democracia brasileira contemporânea.

\section{A díade direita-esquerda nas manifestações de junho de 2013}

O presente artigo defende que as ideologias políticas tradicionais como a velha díade direita e esquerda compareceram nos eventos de junho de 2013 na cidade de São Paulo. Assim, como forma de sustentar nosso principal argumento, se faz necessário mencionar brevemente o conceito de direita e esquerda mobilizado no trabalho. Como se sabe, o uso corrente da conhecida díade é frequente no mundo político, acadêmico e da opinião pública. Com o fim da URSS em 1989, imaginava-se que a dicotomia fosse perdendo seu significado tradicional, na medida em que os partidos e as políticas governamentais se assemelham em muitos aspectos e pontos de interseção. No entanto, o uso dos termos direita e esquerda (ou esquerda x direita) sempre foi lugar comum na esfera política e um verdadeiro balizador desse universo. A díade é usada para indicar a dicotomia do mundo político, significando posições antagônicas entre dois polos constantemente em conflito e disputa. Mas, como se caracterizam estes polos? Afinal, todo o universo político pode ser reduzido ao espectro direita e esquerda?

Segundo Norberto Bobbio (1995), “Conhecem-se exemplos de díades em todos os campos do saber. Na esfera política, direita-esquerda não é a única, mas pode ser encontrada onde quer que se queira" (BOBBIO, 1995, p. 32). Ao constituir-se o campo político como um campo constantemente em tensão, torna-se necessário que as ideologias entrem em conflito, constituindo polos opostos que se encontram situados neste universo. Para o filósofo italiano, esta estrutura que é essencial e originariamente antagônica faz permanecer estes dois polos onde 
quer que se esteja. O professor Fernando Scheeffer (2014, p. s/n), citando Madeira e Tarouco (2011), atenta para o fato de que algo pode passar desapercebido neste debate, uma vez que o significado substantivo desta dicotomia esquerda e direita não é um dado a priori. Também Madeira e Tarouco (2011, p. 172), destacam que os significados destes conceitos variaram ao longo do tempo, desde a Revolução Francesa até o século XX, mas que tendem a permanecer como referência viva, principalmente para mapear posições de partidos políticos.

A existência atual da díade na esfera política não é objeto de consenso entre sociólogos e cientistas políticos. Utilizando novamente Scheeffer (2014), que faz uma divisão dos autores que se dedicaram à análise da atualidade ou não da díade em três diferentes grupos: o primeiro grupo, representados principalmente pelo sociólogo Emir Sader, afirma que a esquerda luta por transformações que resultem na instauração de uma ordem social e econômica diferente da ordem capitalista, enquanto a direita é a favor da manutenção da ordem social e do status quo. O segundo grupo de intérpretes, defende a tese de que as ideologias políticas chegaram ao seu termo final, sustentando o argumento de que a democracia liberal foi superior a todas as formas alternativas de organização da sociedade coroando o capitalismo como o estágio mais avançado da civilização humana. Posição representada pelo filósofo conservador norte-americano Francis Fukuyama em sua conhecida obra "O Fim da História e o Último Homem”. Essa concepção tornou-se conhecida ao afirmar que o momento atual representaria ao fim da história e consequentemente o fim do velho antagonismo entre ideologias políticas e visões de mundo. Já o terceiro grupo de intérpretes acredita que a derrocada da URSS não significa obrigatoriamente o fim da díade esquerda-direita, mas sim uma nova configuração que deve ser encontrada de uma forma mais analítica; este último grupo representa a maioria dos autores.

Para Heywood (2010, apud SCHEEFFER, 2014), nessa nova configuração políticadiscursiva, é fundamental considerar a transição das sociedades industriais para sociedades pósindustriais na qual normalmente está associado um abandono das demandas clássicas da população e dos movimentos sociais. Para o autor, a mudança de enfoque da economia para a cultura fez nascerem novas ideologias, valores e atitudes diante da política. Scheeffer indica que “... as novas ideologias, diferentes das ideologias clássicas, enfatizam fatores como gênero, cultura, etnia. Ganha destaque a 'política da diferença' e declina a política da emancipação universal" (2014, p. s/n). Para o autor, é necessário repensar a tradicional díade a partir de um novo mapeamento das ideologias políticas contemporâneas, dada a complexidade do campo político atual e emergência de novos temas e demandas. Do mesmo modo que há uma perda de sentido das ideologias tradicionais, apontar o fim das ideologias, e também o fim da história, seria presenciar um mundo sem idealidades de futuro, pois as ideologias são exatamente isso. 
O relevante é provocar o debate sobre as ideologias políticas contemporâneas como forma de contribuir para o esforço em elaborar um novo mapa conceitual que dê conta da realidade, principalmente para o caso brasileiro (SCHEEFFER, 2014).

Para o eminente filósofo italiano Norberto Bobbio (1995), a dicotomia entre esquerda e direita na política representa os ideais de liberdade e igualdade, presentes na Revolução Francesa, onde a díade encontra sua origem histórica. O primeiro termo, a noção de liberdade, não seria capaz de definir direita e esquerda, uma vez que a complexidade da realidade dos governos informa elementos contraditórios, ou seja, a história presenciou governos de esquerda autoritários e esquerda liberal, assim como governos de direita autoritários e direita liberal. Já o segundo termo de Bobbio, o ideal de igualdade, seria o mais conciso para definir os campos desta díade.

Mesmo que para o autor, não se possa caracterizar a esquerda como única força política capaz de acabar com todas as desigualdades e a direita comprometida com a manutenção das desigualdades, este é o critério que melhor caracteriza a distinção entre os campos, já que “(...) De um lado, estão aqueles que consideram que os homens são mais iguais que desiguais, de outro, aqueles que consideram que são mais desiguais que iguais" (BOBBIO, 1995, p. 105). A esquerda defende a noção que as desigualdades surgem no seio da própria estrutura social, propondo, portanto, políticas e utopias que procurem a diminuição das desigualdades consideradas elimináveis. De outro lado a direita, defensora do argumento de que as desigualdades são naturais e intrínseca aos indivíduos, apoiando-se na tese de que desigualdades são inerentes e intransponíveis. Desta forma, nas palavras de Bobbio

\footnotetext{
... o elemento que melhor caracteriza as doutrinas que se chamam de "esquerda", e como tais tem sido reconhecidas é o igualitarismo, desde que entendido, repito, não como a utopia de uma sociedade em que todos são iguais em tudo, mas como tendência, de um lado, a exaltar mais o que faz os homens iguais do que o que os faz desiguais, e de outro, em termos práticos, a favorecer as políticas que objetivam tornar mais iguais os desiguais. (BOBBIO, 1995, p. 110)
}

Madeira e Tarouco citando Singer (2002, apud Tarouco e Madeira, 2013), ao apontar a especificidade do caso brasileiro, defendem que no Brasil não é a questão da igualdade que divide a díade esquerda e a direita, mas a forma de alcançá-la. A direita procura alcançar a igualdade sem ameaçar a ordem, para isso busca reforçar a autoridade do Estado. A esquerda, porém, questiona a autoridade do Estado quando este reprime os movimentos e partidos igualitaristas. Bresser-Pereira (2006) articula uma teoria que vai de encontro ao que pensa Singer. Para o conhecido economista brasileiro, “... o elemento central dessa definição está na oposição entre ordem e justiça" (2006, p. 74). Desse modo, os movimentos e partidos de direita defendem o modelo de um país capitalista e democrático, baseado na ordem e no status quo, Barbarói, Santa Cruz do Sul, n.53, p.<01-25>,jan./jun. 2019 
enquanto a esquerda está disposta a sacrificar a ordem em nome da justiça. Porém, a análise de Bresser opõe ordem à justiça, fazendo acreditar que a ordem é injusta e subverte-la levaria as correções dessa injustiça. Madeira e Tarouco (2013, p. 159) apontam o fato de que no caso brasileiro há que se levar em consideração a posição política em relação ao regime militar (1964-1985), identificada com uma postura de direita.

Para as finalidades deste artigo, parte-se da hipótese de que as referências de esquerda e direita foram relevantes no início dos movimentos de junho de 2013. Como se sabe, os protestos da cidade de São Paulo surgiram a partir de pequenos grupos de esquerda, que adotaram uma postura contrária à decisão tomada pela Prefeitura Municipal de São Paulo de aumento das passagens do transporte coletivo. Esses movimentos de grupos estudantis radicalizados, possuem uma pauta igualitarista e crítica da ordem, e buscam através de pressão social, defender demandas junto ao Estado, mesmo que seus métodos de cobrança representem uma ameaça à ordem. Ao cobrar a revogação do aumento dos preços da passagem, esses movimentos buscavam diminuir os custos para os estudantes que utilizam o transporte urbano, que são, em grande maioria, os mais pobres.

\section{Os Movimentos de Junho de 2013 em São Paulo}

Os movimentos de junho de 2013 na cidade de São Paulo apresentaram uma dinâmica que pode ser dividida em três momentos. A partir da conhecida análise de André Singer (2013) sobre as ideologias cruzadas dos protestos de junho, referência essencial para este artigo, procuramos argumentar que este entrecruzamento de ideologias não ocorreu de modo pacífico nas ruas, mas com registro de violência e tensão entre diferentes grupos sociais e políticos. Embora a hipótese das "ideologias cruzadas" seja interessante como forma de análise dos movimentos de protesto, ainda há lacunas e questões não devidamente respondidas sobre essas ideologias e motivações de 2013 na cidade de São Paulo. Neste trabalho, optamos por dividir as manifestações de junho em três momentos distintos, como segue a partir de agora.

Em um primeiro momento, os protestos foram convocados por coletivos formados por grupos de estudantes de esquerda e movimentos sociais de jovens ligados a partidos políticos de esquerda, como o PSOL (Partido Socialismo e Liberdade), PSTU (Partido Socialista dos Trabalhadores Unificado) e mesmo o PT (Partido dos Trabalhadores), partido do então prefeito municipal à época, Fernando Haddad (2013-2016). Os atos de protesto contra o aumento das tarifas do transporte foram respondidos com violência e duramente reprimidos pela Polícia Militar estadual. As ruas da cidade de São Paulo tornaram se campos de batalha e conflitos violentos entre os jovens manifestantes e a polícia paulista. Mobilizados na luta pela revogação 
do aumento do preço da passagem do transporte urbano, estes grupos de esquerda radical foram barrados pelas tropas de choque da Polícia Militar e em grande parte, aqueles atos de protesto iniciais foram marcados pela intensidade dos conflitos de rua.

O segundo momento dos protestos de junho de 2013 foi marcado pela adesão de um público que até então não fazia parte dos atos iniciais. A participação de grandes contingentes populacionais transformou os atos pela redução de 20 centavos no preço da passagem numa verdadeira manifestação de massa. Neste segundo momento, a profusão de pautas e ideologias fica difusa e compreender os protestos do ponto de vista ideológico torna-se problemático, visto que então não se encontra claramente uma direção única ou uma pauta unificada. O número de pessoas nos protestos chegou a milhares, se espalhando por várias cidades do país assumindo uma dimensão nacional. Neste contexto, as manifestações de massa atingem diretamente o governo federal sob a Presidência de Dilma Rousseff do PT (2010-2014) e questões a nível nacional como a qualidade da educação pública, dos serviços de saúde, etc. começam a ser colocados em pauta no interior do movimento. Este é o momento de maior adesão do grande público.

No terceiro momento dos protestos de junho de 2013, o cruzamento ideológico manifestado anteriormente já não pode mais ser encontrado facilmente, pelo contrário, há um conflito direto entre os diferentes grupos e atores. Como se observou, um desses momentos de conflito ocorreu com a expulsão dos movimentos e grupos ligados à partidos de esquerda, como o PT e outros partidos. O próprio Movimento Passe Livre que organizara os atos anteriores também acaba sendo rejeitado. Este é o momento que as marchas tomam novos rumos, pautas diversas alcançam os manifestantes que se mobilizaram neste terceiro momento, e bandeiras como "contra a corrupção", "mais qualidade em saúde e educação" ou "contra os partidos e políticos" ganham definitivamente as ruas. Neste terceiro momento dos atos de junho, esta guinada atingiu principalmente o governo federal e acabou por resultar na grande queda de aprovação do governo da presidente Dilma Rousseff (PT).

É necessário assinalar que a divisão das manifestações de junho em momentos distintos não apresenta em si, nenhuma novidade. Autores como Gohn (2015) e Singer (2013) também pensaram as manifestações de junho de 2013 a partir de momentos distintos. Entretanto, em nosso artigo há uma pequena divergência em relação às divisões cronológicas de cada momento dos protestos de junho. Passemos, assim, a descrevê-los.

\section{$1^{\circ}$ Momento}

O começo do mês de junho é marcado pelas manifestações populares na Turquia. Inspirados pelos movimentos da chamada Primavera Árabe iniciadas na Tunísia em 2010 
(Gohn, 2015), os manifestantes turcos ocupam a praça Taksin e se envolvem em confrontos violentos com a polícia local, os atos se espalham pelo país, impulsionados principalmente pelas redes sociais. O exemplo demonstra que o caso da Turquia não se encontra descolado de uma onda de manifestações globais que atravessava Europa, Ásia e América do Norte, como o movimento Occupy Wall Street - EUA. Desse modo, é preciso inserir as manifestações de junho de 2013 no Brasil numa perspectiva global, marcado por uma onda de protestos mundo afora. Há evidentemente elementos em comum nesse contexto internacional, como o uso rápido das redes sociais como forma de mobilização.

O dia 6 de junho é o dia do primeiro ato do Movimento Passe Livre (MPL) contra a elevação da tarifa do transporte público em São Paulo. O protesto é marcado pelo confronto com a polícia. Os atos intensificam-se no dia posterior, dia 7 de junho de 2013, sexta-feira, quando se registra um aumento no número de manifestantes nas ruas. As marcas do protesto são as mesmas do dia anterior: confronto com a polícia, rastros de depredações de bens públicos e privados e violência. $\mathrm{O}$ dia 11 de junho marca o mais violento e mais intenso dos protestos até aquele momento, além do MPL - que organizou os atos anteriores- somaram-se grupos organizados de jovens de partidos de esquerda, posicionando-se em notas oficiais à imprensa. Outros coletivos também se somaram às marchas neste terceiro ato, entre eles, o Black Bloc e o Anonymous.

Em artigo instigante que analisa a atuação do MPL desde seu surgimento em meados da década de 2000, Monika Dowbor e José Szwako argumentam que "a interação conflituosa e de risco é a performance privilegiada do MPL, é seu roteiro posto e encenado num palco de interação com antagonistas igualmente dispostos ao conflito" (DOWBOR; SZWAKO, 2013, p. $50)$.

Segundo Gohn (2015),

[...] Em São Paulo o MPL faz protestos desde 2006, quando houve aumento da tarifa de $\mathrm{R} \$ 2,00$ para $\mathrm{R} \$ 2,30$. Em 2010 acorrentaram-se a catracas na Secretaria Municipal de Transportes quando a tarifa subiu R $\$ 2,70$; e em 2011, quando o ex-prefeito G. Kassab aumentou de $\mathrm{R} \$ 2,70$ para $\mathrm{R} \$ 3,00$ os ônibus, o MPL fez uma dezena de atos de protesto, paralisou o trânsito, assim como co-organizou o famoso "churrascão da gente diferenciada" (ato de protesto contra moradores do bairro tradicional de Higienópolis que não queriam uma estação de metrô na sua região) (GOHN, 2015, p. 46).

Portanto, o movimento possui um histórico de manifestações e atos de protesto em sua forma de ação política, embora nenhum deles com confrontos tão violentos como ocorrido nas manifestações de junho de 2013. O Movimento Passe Livre se intitula "um movimento 
horizontal, autônomo, independente e apartidário, mas não antipartidário"2 (Apud GOHN, p. 46). E conta com muitos integrantes filiados a partidos de esquerda como PT, PSOL, PSTU e PCO.

Se os protestos do dia 11 de junho foram os mais intensos até o momento, os atos do dia 13 de junho, quinta-feira, superaram os dias anteriores e marcaram uma grande guinada na opinião pública. A capa do jornal Folha de São Paulo no dia 14 de junho, "Polícia reage com violência a protesto e São Paulo vive noite de caos", com a imagem de policiais agredindo com cacetetes e escudos jovens em um bar na Av. Paulista, principal local dos protestos, é representativa. Neste dia o número de pessoas na rua se elevou consideravelmente. Se até aquele momento, os atos se reduziam a uma minoria, embora não tão pequena, formada sobretudo por jovens em protesto contra o aumento da passagem de ônibus, a partir do dia 13 de junho, a opinião pública adere às marchas, engrossando as fileiras dos atos, multiplicando as demandas e o risco de conflitos. A partir do dia 13 tem início o segundo momento dos movimentos do mês de junho, marcados então pela difusão de pautas, multiplicação de demandas - "parecia ser contra tudo"- e o cruzamento de ideologias e classes sociais.

Mais um fato relevante deste 13 de junho merece ser destacado: 100 manifestantes feridos, 192 detidos, a imagem de muitos em fuga pelas ruas e de pessoas agredidas em bares pela Avenida Paulista, muitos deles jornalistas agredidos pela Polícia Militar. Tanto o governador paulista Geraldo Alckmin (PSDB) quanto o prefeito municipal Fernando Haddad (PT), se posicionam contra a violência nos atos e defendem a ação da polícia militar e da GCM como mantenedoras da ordem. Como afirmaram Dowbor e Szwako sobre as ações do MPL:

\begin{abstract}
... a luta pelo "passe livre" transbordou a própria performance do MPL, tornando-se um ciclo de protestos e sendo apropriado pelo público maior, a partir do momento em que a plateia acessou e criticou a reação desproporcional da polícia paulista diante do movimento àquela mesma noite. (DOWBOR e SZWACKO, 2013, p. 55)
\end{abstract}

\title{
$2^{\circ}$ Momento
}

No dia 16 de junho, domingo, reportagem na Folha de São Paulo aponta que cerca de 131.246 pessoas confirmavam presença em evento do Facebook, convocando para os próximos atos do dia 17 de junho (Folha de São Paulo, 16/6/2013, C1). Este é o momento que o protesto ganha adesão de outros setores da sociedade que até então não estavam presentes nos atos anteriores. Como se pode notar, no primeiro momento, convocados pelo Movimento Passe Livre, os atos eram formados basicamente por estudantes e trabalhadores, em sua grande maioria jovens, muitos deles filiados a partidos de esquerda - por isso a importância do MPL

\footnotetext{
${ }^{2}$ Segundo seu site. Disponível em: www.saopaulo.mpl.org.br Barbarói, Santa Cruz do Sul, n.53, p.<01-25>,jan./jun. 2019
} 
se expressar como apartidário, mas não antipartidário- ao protestaram contra o aumento das passagens de ônibus na cidade de São Paulo, que passara de $\mathrm{R}$ \$, 00 para $\mathrm{R}$ \$ 3,20 no começo do mês de junho. Aos atos foram somando-se outros atores sociais com o passar dos dias, como a incorporação de grupos como o Anonymous e o Black Blocs ${ }^{3}$.

O primeiro sinal de que os protestos de junho assumiram uma nova dimensão política, não se restringindo apenas ao contexto da cidade de São Paulo ou mesmo diretamente contra o governo estadual, apareceu já no domingo, 16 de junho. Na abertura da Copa das Confederações ${ }^{4}$, a presidente Dilma Rousseff foi vaiada por uma grande parte dos presentes no Estádio Nacional Mané Garrincha, em Brasília, enquanto anunciava a abertura do evento internacional. Na segunda-feira, 17 de junho, estavam marcados novos atos em São Paulo, e os debates na página oficial do MPL no Facebook apontam para novos rumos. Como se disse, as pautas iniciais do MPL eram centradas basicamente no protesto contra o aumento da passagem, mas neste segundo momento, outros temas e demandas começam a aparecer, como exemplo cita-se: mais investimentos em educação, o combate à corrupção na esfera política, o fim de privilégios a políticos, etc. Se a demanda inicial era contra os $\mathrm{R} \$ 0,20$ na tarifa do ônibus, agora o discurso de grande parte dos participantes e dos debates via Facebook é de que "não é só pelos 20 centavos". Outro indicador importante do segundo momento dos protestos de junho diz respeito ao antipartidarismo e à rejeição aos partidos políticos e movimentos organizados. Os mais exaltados nas discussões nas redes sociais falavam em queimar bandeiras dos partidos políticos que se aproximassem das marchas.

Os atos da segunda-feira, 17 de junho, apresentava nas ruas tudo o que se esperava do ponto de vista da dimensão que assumiu. Assiste-se pelo Brasil todo manifestações nas principais capitais do país, ao menos 12 capitais registraram atos de protesto. Nas imagens da capa do Caderno Cotidiano ${ }^{5}$ do jornal Folha de São Paulo, percebe-se que as mensagens escritas em folhas de cartolina (os atos de junho de 2013 foram bastante registrados nas folhas de

\footnotetext{
${ }^{3}$ Em seu livro, Gohn (2014) dedica algumas páginas para analisar esses coletivos em especial. Segundo a autora, em relação ao Anonymous, trata-se de um grupo internacional de ativismo digital, o anonymous faz uso de programas na internet pra sobrecarregar sites oficiais de escolha para seu ataque, fazendo com que eles saiam do ar por algum tempo, denominam a atividade de cyberativismo ou hacker; quanto ao Black Blocs, trata-se de um grupo de inspiração anarquista, no início ligado ao movimento autonomista da Alemanha Ocidental na década de 1970, o grupo utiliza-se de ataques aos símbolos do capital - como agências bancárias e grandes empresas globais, atua nos protestos fazendo frente à polícia nos conflitos, utilizando-se de escudos feitos na rua, máscaras de gás, pedras e paus, segundo os ativistas, para defender o restante dos manifestantes quando são dispersados pelas tropas policiais. Para um melhor aprofundamento destes grupos ver Gohn (2014, pp. 51-63).

${ }^{4} \mathrm{O}$ "estrondoso" mês de junho coincidiu com o evento da Copa das Confederações, torneio de futebol organizado pela FIFA (Fédération Internationale de Football Association) e que teve pela primeira vez o Brasil como país anfitrião.

${ }^{5}$ Folha de São Paulo, 18/06/2013, C1
} 
cartolina, que continham as pautas dos manifestantes) são bastante diversas, enquanto algumas relembram a pauta dos 20 centavos do aumento na passagem de ônibus - "R\$ 3,20 é roubo!!" -, outros exclamam exatamente o contrário - "Não é pelos 20 centavos!”. Às tradicionais cores vermelho e preto, que marcaram o primeiro momento dos protestos, soma-se o verde e amarelo da bandeira com frases e palavras de ordem exaltando trechos do hino nacional brasileiro. Se no último dia 13, o que marcou os protestos foi a violência policial, nos protestos do dia 17 a violência veio também do próprio grupo de protestantes, e os alvos foram principalmente as instituições públicas e de governo. Situação semelhante pôde ser observada em outras grandes cidades brasileiras.

Dados fornecidos por pesquisa realizada pelo Instituto Datafolha neste dia ajuda a revelar um pouco o perfil da manifestação do dia 17 de junho (Folha de São Paulo, 18/06/2013, C4). Segundo o jornal, aproximadamente 65 mil pessoas se reuniram no Largo da Batata, local marcado para o início dos atos na cidade de São Paulo; 84\% dos participantes não possuem preferência partidária; $71 \%$ participavam pela primeira vez dos atos; a maioria de jovens, entre 26 e 35 anos; 77\% possuíam nível superior. Segundo a pesquisa, os motivos para a adesão ao movimento de protesto são diversos, com destaque para: o aumento da passagem, contra a corrupção, contra a violência ou a repressão policial, contra os políticos, por um transporte de melhor qualidade; E por fim, 81\% se informaram dos atos via Facebook, revelando a força das redes sociais na atualidade. Pelos dados disponíveis pelo Datafolha, podemos perceber que a grande maioria dos participantes do dia 17 de junho eram estreantes em manifestações públicas, tendo participado pela primeira vez em algum ato de protesto. Estes novos grupos de escassa experiência política que engrossaram os movimentos de junho com fortes referências à rejeição da política assim chamada tradicional e à elite política como um todo, acabou por dar o tom dos protestos em sua dimensão nacional.

No dia 18 de junho, terça-feira, um novo ato nas ruas de São Paulo com características muito parecidas com o ato de protesto do dia anterior: difusão de demandas, ataques às instituições públicas e presença de 50 mil pessoas, aproximadamente; desta vez, houve também saques à lojas e depredações à várias agências bancárias na capital paulista. Ao final dos atos violentos, novamente houve forte confronto com a polícia militar de São Paulo. É interessante destacar ainda que neste ato do dia 18 de junho, segundo o jornal Folha de São Paulo (19/06/2013, C2), a marcha se dividiu na Av. Paulista e se espalhou pelas ruas do centro da cidade. Enquanto a maior parte seguia pela avenida, um pequeno grupo se dirigiu para a frente da Prefeitura Municipal onde ocorreu uma tentativa de invasão do prédio. Naquele momento, houve uma divisão no interior do grupo de manifestantes: enquanto alguns gritavam "Sem Barbarói, Santa Cruz do Sul, n.53, p.<01-25>, jan./jun. 2019 
Violência!", ou "Sem vandalismo!", outros grupos gritavam "Com vandalismo" e atacaram o prédio da prefeitura.

Um outro elemento que merece destaque na análise das manifestações desses dois dias do mês de junho de 2013, foram os ataques violentos aos órgãos de imprensa tradicionais e os grandes meios de informação. No dia 17 uma parte dos manifestantes seguiu até o prédio dos estúdios de jornalismo da Rede Globo em São Paulo - maior grupo de mídia do Brasil- e no dia 18 um carro da TV Record, que trabalhava na cobertura dos protestos, foi incendiado em frente à Prefeitura Municipal. Este momento das manifestações acaba por demonstrar que o MPL perdeu definitivamente o controle dos protestos, a difusão das pautas aponta que a pauta do MPL já não é a única nas ruas e sua preocupação com a violência indica que o grupo já não tem mais o controle sobre os atos e sobre a direção das marchas.

Os protestos deste segundo momento do mês de junho de 2013, portanto, foram marcadas pela difusão das demandas, heterogeneidade dos grupos participantes e do perfil dos manifestantes, mas também pelo conflito entre grupos de manifestantes que aderiram ao protesto. $\mathrm{O}$ uso ou não da violência contribuiu para dividir os grupos. A diferença principal entre os dois momentos é a fragmentação dos atos de protesto, apontando claramente um entrecruzamento ideológico e de classes como bem indicou André Singer (2013). No dia 19 de junho é anunciado então a queda das tarifas de ônibus na cidade de São Paulo e juntamente com ela mais 12 grandes cidades, incluindo outras 6 capitais - Rio de Janeiro, Cuiabá, Recife, João Pessoa, Porto Alegre e Aracajú. Os protestos surtiram efeito no poder público e a pauta do MPL logrou êxito em caráter e dimensão nacional.

Neste segundo momento dos protestos de junho de 2013, a reação dos governantes em nível nacional foi de surpresa e muitas vezes atônita e com dificuldades de apresentar uma resposta. Na ocasião, a presidente Dilma Rousseff (PT) manifestou-se exaltando os atos, como parte normal da democracia, mas não indicou nenhuma medida a ser tomada. O que parece é que a força e a proporção que as manifestações tomaram nesta última semana de junho pegou toda classe política de surpresa. O governador de São Paulo, Geraldo Alckmin (PSDB), que no primeiro momento defendeu a ação repressiva da polícia militar, logo que os protestos ganharam intensidade e proporção tirou a tropa de choque da rua e recuou na ação policial, proibindo inclusive o uso de bala de borracha pela PM. O prefeito de São Paulo, Fernando Haddad (PT), que no começo da semana marcou reunião com o MPL afirmando que não haveria possibilidade de diminuir o preço das passagens de ônibus, voltou atrás no decorrer da mesma semana anunciando a queda nos preços das passagens. 


\section{$3^{\circ}$ Momento}

Como tentamos demonstrar, o primeiro momento dos protestos foi marcado por uma orientação de esquerda, contra o aumento das passagens de ônibus. O segundo momento, foi marcado pela fragmentação de pautas e o cruzamento de ideologias e classes. A principal diferença política entre o primeiro e o segundo momento é que no primeiro, apenas o governo municipal é atingido, enquanto no segundo, os governos estadual e federal são alvo dos protestos. Neste terceiro momento dos protestos, o cruzamento de ideologias se desfaz, e no lugar entra em cena o forte rechaço aos partidos políticos e às bandeiras de esquerda, o que acaba por separar os atos e diminuir a força dos movimentos de protesto. Os movimentos sociais à esquerda organizam marchas nas periferias da cidade, enquanto os atos que atingem mais particularmente o governo da presidente Dilma Rousseff (PT) se espalham pelo país e são marcados por pautas difusas e particulares em cada um dos casos. Este que denominamos terceiro momento tem início nas marchas marcadas para o dia 20 de junho, quinta-feira, quando há confronto nas ruas entre grupos e partidos de esquerda e uma parte dos manifestantes que se declara apartidária.

Os atos do dia 20 de junho, quinta-feira, foram os maiores registrados deste mês, segundo números fornecidos pelo Datafolha cerca de 110 mil pessoas estavam na Av. Paulista. $\mathrm{O}$ ato havia sido marcado pelo MPL para comemorar a queda no preço das passagens. $\mathrm{O}$ dia 20, no entanto, foi marcado por confronto entre grupos partidários de esquerda (o mais atingido foi o PT, mas também militantes do PSOL, PSTU, PCO) juntamente com o próprio MPL e grupos que se autodenominavam apartidários e antipartidários. O cruzamento de ideologias que marcou os protestos no segundo momento de junho já não estava presente de forma tão pacífica, em seu lugar entra o rechaço aos grupos de esquerda e aos partidos políticos de esquerda, principalmente o PT. A ligação do partido com a corrupção começa a se tornar corrente tendo em vista os envolvimentos do PT nos escândalos do "mensalão". Nota-se também que a ligação do MPL com os partidos de esquerda acaba com sua exclusão dos protestos que inicialmente eram convocados pelo próprio movimento.

No mesmo dia 20 de junho, o MPL divulgou nota à imprensa em que repudiava as ações contra os partidos políticos empunhada por outros movimentos. O grupo mostrou preocupação com o que eles chamaram de "entrada de grupos conservadores nas marchas" (Folha de São Paulo, 22/06/2013, C5). Depois destes atos do dia 20 de junho, o MPL muda a estratégia de protesto, ao contrário dos atos de rua como antes, o grupo passa a realizar reuniões públicas para esclarecer suas pautas. Percebe-se que esta é uma forma do MPL se retirar dos atos que, segundo o próprio coletivo, tomavam ares mais à direita e a partir daí o movimento passa a 
adotar posturas para se diferenciar desses grupos, afirmando sua característica de movimento de esquerda.

Em pesquisa do instituto Datafolha realizada neste dia 20 de junho nos atos da Av. Paulista, demonstra que a tarifa zero é defendida por apenas $25 \%$ dos manifestantes, em seu lugar entra o tema da "corrupção" como bandeira principal das ruas e, como vimos anteriormente, também a principal causa do confronto com militantes petistas - "mensaleiros". Uma das características principais deste terceiro momento de junho de 2013, foi a pulverização dos protestos, que se espalharam por toda cidade de São Paulo. Diferentemente do segundo momento, onde todas as demandas, apesar de difusas, estavam concentradas em um mesmo espaço, neste terceiro momento elas implodem em espaços geográficos diversificados. Enquanto alguns protestos continuam no centro da cidade, próximos à avenida Paulista, outros rumam para as periferias da cidade e até em aeroportos.

Já no dia 19 de junho, a quarta-feira em que foram derrubados os aumentos da passagem, o MTST (Movimento dos Trabalhadores Sem Teto) organizou um protesto bloqueando estradas na cidade de São Paulo e queimando pneus. As pautas do movimento iam para além das tarifas de ônibus, uma das coordenadoras afirmava "protestamos contra o aumento do custo de vida, dos impostos e contra o preço da Copa do Mundo, que é paga pelos trabalhadores" (Folha de São Paulo, 20/06/2013, C8) ${ }^{6}$. Ainda na periferia da cidade, na estrada do M'Boi Mirim, moradores do Capão Redondo, periferia do extremo sul de São Paulo, cerca de mil manifestantes também se reuniram para protestar organizados pelo Movimento dos Trabalhadores Sem Teto (MTST), Movimento Periferia Ativa e alguns integrantes do Movimento Passe Livre (MPL). Entre suas pautas estavam o transporte público, moradia (a pauta histórica do MTST) e melhorias nos serviços de saúde.

Na terça-feira, no dia 25 de junho de 2013, ainda ocorreram três protestos na periferia de São Paulo organizados pelos mesmos movimentos de antes, como o MTST e o Periferia Ativa com apoio do MPL. Novamente, entre as suas pautas estava a questão da moradia - os manifestantes pediam controle no valor dos aluguéis e o fim dos despejos, a tarifa zero para o transporte público (a pauta do MPL), a desmilitarização da polícia militar e aumento nos investimentos em saúde e educação e críticas à realização da Copa do Mundo de futebol no país. No mesmo dia, o governador paulista Geraldo Alckmin (PSDB) anunciou aumento do

\footnotetext{
${ }^{6}$ Outra ressalva deve ser feita aqui em relação à Copa do Mundo. Este é outro evento realizado pela FIFA que tem o Brasil como sua sede, o evento será realizado em 2014, portanto 1 ano após estes atos de junho e até lá registrará novos protestos contra.
} 
benefício às famílias que aguardavam por moradias dos programas do governo estadual, sinal claro de tentativa de atendimento a essas demandas populares.

No centro da cidade de São Paulo, entre pautas difundidas e dispersas, são organizados os mais diversos atos nas ruas: contra a PEC37, contra a corrupção, movimentos organizados pela comunidade LGBT (gays, lésbicas, bissexuais e transexuais) e movimentos organizados por médicos. Pesquisa Datafolha, realizada no dia 21 de junho, aponta que a pauta do MPL é quase irrelevante para grande parte da população, cuja pesquisa revela possuir outras preocupações.

Na pesquisa realizada pelo instituto Datafolha no dia 20 de junho com manifestantes na Av. Paulista, os grupos identificados como extremos liberais representavam a maioria dos manifestantes, e se identificavam majoritariamente como de "centro" no espectro políticoideológico; a esquerda passou a perder espaço nos movimentos, diferentemente do primeiro momento que organizava os atos inclusive com grande participação de militantes de partidos políticos de esquerda. A diferença é exatamente a dispersão dos atos, diferentemente do segundo momento, os atos deste terceiro momento estão completamente dispersos e com pautas bem mais específicas, não havendo mais cruzamento entre ideologias e classes sociais como no segundo momento dos protestos. Após o dia 20 de junho a dispersão é a marca dos protestos em São Paulo.

\title{
Hegemonia e protesto nos movimentos de junho de 2013
}

Recorre-se agora ao conceito de hegemonia como categoria para analisar o que ocorreu nas ruas de São Paulo durante o mês de junho de 2013.

Segundo Alves (2010)

\begin{abstract}
A noção de hegemonia propõe uma nova relação entre estrutura e superestrutura e tenta se distanciar da determinação da primeira sobre a segunda, mostrando a centralidade das superestruturas na análise das sociedades avançadas. Nesse contexto, a sociedade civil adquire um papel central, bem como a ideologia, que aparece como constitutiva das relações sociais. (ALVES, 2010, p. 71)
\end{abstract}

Ou seja, a proposta de análise procura tirar a centralidade da determinação econômica e buscar nas relações políticas e sociais suas nuances ideológicas e os processos que estão no seio da sociedade civil. Ainda segundo a autora, o conceito surge em um período de crise do marxismo, dado sua ênfase da necessidade histórica e da dificuldade de enfrentar as contingências dos processos sociais (ALVES, 2010). Para Laclau e Mouffe (1987, p. 46) a hegemonia é incompatível com a ideia de um desenvolvimento linear e imutável. Laclau e Mouffe (1987), destacam que ao falar em hegemonia deve-se mencionar teóricos da II 
Internacional como Kautsky e Rosa Luxemburgo ou então Lênin, mas foi em Gramsci que o conceito foi melhor trabalhado teoricamente tendo em conta seu caráter de articulação, mesmo ainda ambíguo e limitado. Alves citando Coutinho chama atenção para as referências de Lênin no conceito de hegemonia. Segundo o autor, embora Lênin não tenha falado diretamente em hegemonia, Gramsci atribui a ele a origem deste conceito e tem grande influência no seu pensamento político (COUTINHO, 1992, apud ALVES, 2010).

O Dicionário Gramsciano ${ }^{7}$ (2017, pp. 365-368) ao abordar o verbete hegemonia atenta para o fato de que

No que diz respeito ao significado que deve ser atribuído a "hegemonia", desde o início ..., Gramsci oscila entre um sentido mais restrito de "direção" em oposição a "domínio", e um mais amplo e compreensivo de ambos (direção mais domínio). (Dicionário gramsciano, 2017, pp. 365-366)

Para Laclau e Mouffe, a primeira vez que o conceito de hegemonia é empregado pelo autor é no texto "Notas sobre a questão Meridional” de 1926.

(...) El proletariado puede llegar a ser la clase dirigente y dominante en la medida en que logre crear un sistema de alianzas que le permita movilizar a la mayoría de la población trabajadora contra el capitalismo y el estado burguês. En Italia, dadas las reales relaciones de clase que alli existen, esto significa: en la medida en que logre ganar el consentimiento de las amplias masas campesinas (...) (GRAMSCI Apud LACLAU E MOUFFE, 1987, p. 115)

Deste excerto pode se notar o caráter ambíguo do uso do conceito em Gramsci, como destacado pelo Dicionário. O uso dos termos “dirigente" e "dominante" destacam os níveis nos quais a hegemonia deve ser conquistada ou disputada. Alves, recorrendo a Portelli (1977, apud ALVES, 2010), aponta que a hegemonia, no sentido gramsciano, não é exercida sobre toda a sociedade, mas sobre as classes aliadas, já sobre as classes opositoras, a classe dirigente usa da força. Ao exercer a hegemonia no sentido de "direção" é que se destaca seu caráter articulatório, ao contrário, ao exercer o domínio, o sentido torna-se de coerção. Podemos dizer que a classe dominante exerce direção e coerção sobre as classes dominadas.

Esse caráter articulatório do conceito em Gramsci é apontado como o grande passo dado pela teoria marxista, pois através do conceito de bloco histórico introduz uma complexidade radical e profunda na teorização do social (LACLAU E MOUFFE, 1987, p. 151). Porém, para os autores,

... incluso, para Gramsci, el sujeto hegemónico constituye el núcleo último de su identidade en un punto exterior al espacio que articula: la logica de la hegemonía no ha desplegado todos sus efectos desconstrutivos en el espacio teórico del marxismo clásico. (LACLAU E MOUFFE, 1987, p. 151)

\footnotetext{
${ }^{7}$ Cita-se aqui primeiramente o Dicionário Gramsciano devido ao caráter dos escritos de Gramsci, que dificulta uma articulação de seus conceitos em poucas páginas.
}

Barbarói, Santa Cruz do Sul, n.53, p.<01-25>, jan./jun. 2019 
O que os autores apontam é que ao construir um sujeito hegemônico que detém os rumos da história nas suas mãos (a classe trabalhadora), o marxismo não consegue superar a lógica da necessidade histórica e parte da interpretação de uma realidade social suturada que encontra no proletariado os fins da constituição hegemônica. Ou seja, o sujeito hegemônico é externo, pois já possui a finalidade das disputas sociais e políticas seja ele a classe ou o partido.

Ao contrário destas análises, o que Laclau e Mouffe propõem é partir da lógica da contingência e interpretar a realidade social como um campo aberto e não suturado como na interpretação marxista clássica. Assim, se a realidade é contingente, os sujeitos sociais precisam disputar os rumos da história, sendo o proletariado apenas um deles. A crítica é que Gramsci estava preso a uma visão ontológica para analisar o social, assim sendo só conseguia observar os fenômenos a partir de sua visão de classe e política. Mas a realidade se apresenta muito mais complexa e precária. “(...) No existe un espacio suturado que podamos concebir como una 'sociedad', ya que lo social carecería de esencia”' (LACLAU E MOUFFE, 1987, p. 161).

Daniel de Mendonça (2007, p. 250) atenta para o fato de que a categoria de hegemonia para Laclau está imersa em um contexto em que a noção de discurso é central. Isso requer dizer que

... numa análise que tenha por base a teoria do discurso, não há como se constituir
previamente sentidos sociais ou se levar em consideração identidades ou movimentos
sociais totalmente constituídos com projetos políticos existentes "desde sempre" em
direção a um objetivo preciso (teleológico). (MENDONÇA, 2007, p. 250)

Para analisar esta realidade que se forma e se mostra muito mais complexa, Laclau e Mouffe utilizam o conceito de "sobredeterminação", sendo este a ideia de que um campo externo (a história, como construção) e interno (a contingência) são sobredeterminados. "La tensión irresoluble interioridad/exterioridad es la condición de toda práctica social: la necessidad solo existe como limitación parcial del campo de la contingencia" (LACLAU E MOUFFE, 1987, p. 189). É neste campo de disputas contingente e precário, uma vez que não há nada que possa determinar, que as práticas discursivas e os discursos vão disputar a hegemonia. É nesta realidade, diferente da realidade formulada pelo marxismo clássico, que Laclau e Mouffe propõe a interpretação através do conceito de hegemonia. A hegemonia assim é luta, mas é luta em um campo que não possui determinantes e em um campo que está sempre aberto. O campo discursivo.

A hegemonia, para os autores, só pode existir como articulação naquilo que eles denominam campo de práticas articulatórias, pois em um campo fechado sem a abertura para estas práticas jamais pode haver disputa hegemônica. Ou seja, partindo de uma realidade que $a$ 
priori não possui uma essência e uma história já constituída desde seu princípio, a análise laclauniana propõe interpretar as disputas que estão em jogo nesta sociedade a partir da análise dos discursos que disputam o campo hegemônico. E nesta relação de disputa contingencial destaca-se a capacidade de um dos discursos articular e representar outros discursos constituindo uma hegemonia, mas que sempre está em tensão com discursos antagônicos ou contra-hegemônicos. A disputa discursiva não se exauri, pois ela constitui a própria realidade do social, precária e contingente.

Mendonça (2007, p. 251), descreve

\begin{abstract}
A hegemonia é uma relação em que uma determinada identidade, num determinado contexto histórico, de forma precária e contingente, passa a representar, a partir de uma relação equivalencial, múltiplas identidades. (...) No sentido de Laclau, portanto, toda identidade vive numa constante busca a completude, sendo tal busca, contudo, sempre ineficaz. A hegemonia, in contrario sensu à noção de falta constitutiva ou de incompletude identitária, visa a preencher essa ausência de plenitude. (Mendonça, 2007, p. 251)
\end{abstract}

Alves (2010, p. 95) ao apontar os pontos de aproximação e ruptura entre as perspectivas de Gramsci e Laclau e Mouffe, destaca que ambas as abordagens partem da disputa pela hegemonia como constitutiva das relações sociais e privilegiam o momento da articulação política, reconhecem que a hegemonia não é exercida sobre toda a sociedade e defendem a criação de uma nova hegemonia baseada nas articulações com outros grupos que constituem o social. Destaca-se ainda a ênfase dada pelos autores na superestrutura, em contrapartida às analises marxistas mais ortodoxas que tinham como pressuposto a determinação da estrutura econômica sobre as constituições ideológicas e de visão de mundo da sociedade. Porém o principal ponto de ruptura, segundo a autora é que,

... enquanto em Gramsci a hegemonia remete a unidade de todo bloco histórico, Laclau e Mouffe questionam todo tido de sutura, pois consideram que isso seja impossível. Toda tentativa de fechamento e de fixação de sentido é ideológica. Essas posturas refletem diretamente no projeto de sociedade defendido por esses autores. Enquanto Gramsci considera possível a instauração do socialismo e de uma sociedade sem classes, em que o próprio partido e a atividade política desapareceriam, para Laclau e Mouffe não há possibilidade de uma reconciliação final, uma vez que o antagonismo é constitutivo do social e que ele apresenta um caráter aberto e incompleto. (ALVES, 2010, p. 95)

Desse modo, após essa breve introdução sobre o conceito de hegemonia, propõe-se uma interpretação dos fenômenos sociais de junho de 2013 descritos nas seções anteriores, através desta perspectiva teórica, buscando compreender os movimentos de junho de 2013 a partir de uma leitura de disputa hegemônica de diferentes grupos e movimentos sociais. Como buscamos demonstrar na seção anterior, as manifestações de junho de 2013 tiveram início na cidade de São Paulo por atos de protesto de um movimento social organizado, o Movimento Passe Livre Barbarói, Santa Cruz do Sul, n.53, p.<01-25>,jan./jun. 2019 
(MPL), com uma pauta específica: a revogação do aumento nas passagens do transporte público. Os protestos eram formados por jovens estudantes e trabalhadores, muitos ligados a partidos políticos da esquerda brasileira como PSOL, PSTU, PT, etc.

Assim, naquele contexto, entende-se que a pauta da tarifa do transporte público logrou ser hegemônica entre estes grupos sociais, articulando suas demandas e interesses em torno de uma bandeira única: a queda dos 20 centavos no aumento. Conforme a perspectiva gramsciana, o MPL conquistou a hegemonia na direção dos atos neste primeiro momento, pois a pauta do transporte articulou os interesses de um setor da sociedade e de grupos políticos e movimentos sociais levando-os aos protestos sob sua direção. Apesar de o MPL não possuir lideranças verticais, ou seja, organizar-se horizontalmente, conforme o próprio grupo, entende-se que o MPL estava na direção dos atos pois sua pauta conseguiu ser hegemônica naquele momento. Conforme a perspectiva laclauniana, em um momento precário e contingente, tendo em consideração a insatisfação de vários grupos, o MPL e a pauta do transporte público conseguiram conquistar a hegemonia articulando seu interesse e sua identidade às identidades de outros grupos sociais.

No primeiro momento dos atos, essa foi a realidade, porém, a partir do segundo momento, outros grupos e outras identidades vão somar-se as ruas. Esse cruzamento ideológico faz surgir novas demandas, pois, conforme Laclau e Mouffe, a realidade social nunca se esgota e é sempre aberta e contingente. Neste segundo momento, novamente a hegemonia está em jogo, é o momento que os conflitos ideológicos começam a ficar evidentes no interior dos movimentos de junho de 2013. No segundo momento, ao anunciar-se os debates na página oficial do $\mathrm{MPL}^{8}$, já podemos perceber que as dimensões dos protestos ganhavam novos ares e haviam chegado a um grupo que ainda não tinha se somado aos atos anteriores. A pauta dos 20 centavos passa a ser questionada ("não é só por 20 centavos") entrando assim em uma disputa pelos rumos que os protestos viriam a tomar. A presença de partidos políticos tornara-se objeto de questionamento com a entrada de pessoas que se identificavam como antipartidários ou simplesmente não queriam ver os partidos políticos nas ruas. As vaias à presidente Dilma Rousseff (PT) também vinham adicionar novas questões, demonstrando que os atos estavam escapando do universo da cidade de São Paulo e de suas pautas específicas e expandindo-se pelo país, alimentando mais demandas à um novo momento político e social que se torna novamente contingente.

\footnotetext{
${ }^{8}$ Descritos na seção anterior

Barbarói, Santa Cruz do Sul, n.53, p.<01-25>,jan./jun. 2019
} 
Este segundo momento dos protestos de junho de 2013 é marcado pela abertura hegemônica, quando a pauta do MPL precisa disputar o campo discursivo com outros discursos que entram em cena naquele contexto. Alguns antagonismos começam a existir, como é próprio à uma disputa hegemônica. Entre estes antagonismos estão, além das pautas e das diversas demandas das ruas, os conflitos entre partidários e antipartidários, com vandalismo e sem vandalismo. Indicativo desse fato, sugere que os grupos que no primeiro momento dirigiam os atos e tinham a hegemonia das ruas, agora passam a disputar a hegemonia com outras pautas e outros grupos, ou seja, outros discursos. O terceiro momento dos protestos é decisivo. O MPL e os grupos que dirigiam os atos no início perdem efetivamente a hegemonia das ruas e se retiram para atos isolados na periferia da cidade. O dia 20 de junho é o indicador dessa cisão.

No dia 20 de junho os discursos entram em conflito mais aberto, acabando na expulsão de grupos ligados à partidos de esquerda e, consecutivamente do próprio MPL que é um coletivo formado por militantes partidários. Este conflito torna-se visível quando o MPL divulga nota à imprensa, na qual expõe que expulsar os partidos das marchas seria expulsar organizações de uma luta que construíram juntos. O que o MPL não havia notado até o momento é que a disputa hegemônica havia sido perdida. A direção dos protestos de junho já não era mais sua. Neste terceiro momento de junho de 2013, uma pauta passa a ganhar a disputa pelo campo discursivo, a pauta da corrupção que, conforme apontado anteriormente passa a ser defendida por grande parte dos manifestantes. Juntamente ao tema da corrupção, aparece o descontentamento com os políticos e com a política, já que para muitos dos manifestantes, ambas acabam se conciliando na prática, uma vez que a corrupção é vista apenas como corrupção do setor público, mais propriamente daqueles que estão na direção do Estado, a chamada classe política.

A própria expulsão dos partidos políticos e principalmente do PT dos atos, aponta que a pauta hegemônica passa a ser a da corrupção na política, pois a ligação dos partidários à corrupção é um dos motivos para sua hostilização nas ruas - "mensaleiros". Quando o MPL não consegue mais exercer a hegemonia das ruas, vendo sua pauta diluir-se em um universo discursivo muito mais vasto, o grupo se retira e convida seus membros e simpatizantes a retirarem-se dos movimentos. Então passa a articular seus discursos em outra estratégia política, que inclui audiências públicas e o fortalecimento dos movimentos e protestos pela periferia da cidade de São Paulo, juntamente com o MTST e o Movimento Periferia Ativa.

Este último momento dos movimentos de junho de 2013 foi também o momento que os atos se pulverizaram e se tornam mais isolados e heterogêneos. Alguns atos espalhavam-se pela tradicional Avenida Paulista com as pautas mais diversas, outros ainda ocorreram em aeroportos da cidade ou nas periferias, apresentando também pautas específicas e variadas do Barbarói, Santa Cruz do Sul, n.53, p.<01-25>,jan./jun. 2019 
conjunto. Assim, percebe-se no mês de junho, claramente uma pulverização das demandas, quando se agregam outros grupos e outros perfis de manifestantes, o campo discursivo se expande e a hegemonia passa a ser novamente disputada. Olhando por essa lógica, outros discursos passam a disputar o campo hegemônico dos atos. O que torna os protestos de junho heterogêneos e difusos. Nesse último momento dos protestos de junho de 2013 na cidade de São Paulo, a pauta da corrupção dos partidos e políticos torna-se hegemônica entre as demandas que estavam em disputa, e em seguida os movimentos dispersam-se e pulverizam-se, espalhando-se pela cidade e pelo país afora.

\section{Conclusões}

O presente artigo buscou contribuir com os debates acadêmicos sobre as manifestações de junho de 2013, a partir de suas dimensões ideológicas, buscando enquadrá-las dentro do espectro político direita-esquerda. Embora os movimentos de junho 2013 não pareçam apresentar claramente um fácil enquadramento ideológico, dado a complexidade e a fragmentação dos movimentos sociais contemporâneos, acredita-se que é possível encontrar essas referências. Nesse sentido, o trabalho procurou dar conta de articular a teoria de Laclau e Mouffe, e os seus conceitos de hegemonia e disputa discursiva na esfera política e social para compreender a configuração deste espectro ideológico.

O caso dos movimentos de junho de 2013, tornaram-se ícones da explosão de processos sociais mais diversos. Pode-se inclusive defender que 2013 inicia um ciclo de protestos no Brasil, conforme argumenta Alonso (2017). No seu contexto específico, os atos de junho de 2013 são marcados por uma clara liderança e orientação de esquerda, como o Movimento Passe Livre, apoiado por outros grupos e jovens ligados a partidos de esquerda. A pauta do transporte gratuito na cidade de São Paulo, embora motivo de benefícios comprovados no trânsito urbano e na qualidade do ar na cidade, não é pauta dos grandes partidos políticos de esquerda. A questão dos custos financeiros a ser assumidos pelos três diferentes níveis de governo, mesmo num governo do PT na cidade e no federal, afasta os partidos no governo dessa questão. Não é difícil entender que demandas mais radicais de esquerda foram, como sempre, respondidos com o uso da força policial, resultando em conflitos nas ruas da cidade de São Paulo.

Entendidos os movimentos de 2013 como um ato em três diferentes momentos ajuda a entender a complexidade, os conflitos e a forma que assumiram. Se no primeiro momento, há uma hegemonia de um grupo, a partir do segundo momento, há um verdadeiro cruzamento de ideologias e classes nos movimentos. Depois, a partir do último momento dos protestos, esse cruzamento ideológico traçado anteriormente se desfaz. A pauta da tarifa deixa de ser o discurso 
hegemônico e a hegemonia discursiva passa a ser a da corrupção dos partidos e políticos profissionais. Neste último momento, os grupos de esquerda se retiram, cedendo lugar a grupos mais à direita. Alguns desses grupos tornaram-se símbolos da rejeição às esquerdas e ao partido no governo federal e municipal, o PT. Nesse sentido, as relações com um ciclo de protestos que culminou com o afastamento do partido do poder em maio de 2016, é bastante evidente.

Por isso, os estudos sobre os movimentos de junho de 2013 ainda deverão trazer questões novas e enriquecedoras para o debate político e acadêmico sobre a realidade brasileira contemporânea e suas diversas faces de desafiante complexidade para a campo das ciências sociais. De nossa parte, fica a tentativa de contribuir para esse debate que alcança as questões sobre a democracia, as relações Estado e sociedade e as mudanças sociais e políticas que esses protestos acabaram por produzir na sociedade brasileira dos últimos anos.

\title{
POLITICS AND PROTESTS IN RECENT BRAZIL: JUNE 2013 DEMONSTRATIONS IN THE STREETS OF SÃO PAULO
}

\begin{abstract}
The aim of this article is to analyze the protest movements that took place in June 2013 in the city of São Paulo. As we know, these movements or journeys in June attracted the attention of analysts and social scientists of Brazilian life due to their complexity, size and variety of demands. On the other hand, the dimension of the June protests that took place in the city of São Paulo took over the streets in Brazil, also symbolized in practice the beginning of a real cycle of protests in contemporary Brazilian society, with strong impacts on the sphere and forms of organization and social mobilization. The paper tries to understand the movements of June 2013 from its ideological dimension, trying to make it possible to frame the events of June from a political perspective of right or left.
\end{abstract}

Key-words: social movements; june 2013; politics and protest.

\section{REFERENCIAS BIBLIOGRÁFICAS}

ALONSO, A. A Política das Ruas: protestos em São Paulo de Dilma a Temer. Novos

Estudos Cebrap Especial. São Paulo. Jun/2017. Pp. 49-58.

ALONSO, A. MISCHE, A. Changing repertoires and partisan ambivalence in the new brazilian protests. Bulletin of Latin American Research. Vol. 36, n. 2. Abr/2017. Pp. 139280 .

ALVES, A. R. C. O conceito de hegemonia: de Gramsci a Laclau e Mouffe. Revista Lua Nova, n. 80. São Paulo. 2010. Pp. 71-96.

BOBBIO, N. Direita e esquerda: razões e significados de uma distinção política. São Paulo: Editora da Universidade Estadual Paulista, 1995. 
BRESSER-PEREIRA, L. C. O paradoxo da esquerda no Brasil. Novos Estudos Cebrap, ${ }^{\circ}$ 74, 2006.

BRINGEL, B; DOMINGUES, J. C. (orgs.). As jornadas de junho em perspectiva global. Rio de Janeiro. Netsal, IESP/UERJ. 2013.

BUCCI, E. A forma bruta dos protestos: das manifestações de junho de 2013 à queda de Dilma Rousseff em 2016. São Paulo. Companhia das Letras. 2016.

FERES JR, J. ; MIGUEL, L. ; BARBARELA, E. A mídia impressa na cobertura das manifestações de junho. In: Encontro Anual da ANPOCS 38. 2014. Anais. São Paulo: ANPOCS, 2014.

GOHN, M. da G. A sociedade brasileira em movimento: vozes das ruas e seus ecos políticos e sociais. Caderno CRH. Salvador. v. 27, n. 71. Mai/Ago 2014. Pp. 431-441.

Manifestações de junho de 2013 no Brasil e praça dos indignados no mundo. 2 ed. Petrópolis, RJ: Vozes, 2015.

HEYWOOOD, Andrew. Ideologias políticas: do feminismo ao multiculturalismo. São Paulo. 2010. Ideologias políticas: do liberalismo ao fascismo. São Paulo. 2010.

LACLAU, E.; MOUFFE, C. Hegemonía y estrategia socialista: hasta una radicalización de la democracia. Siglo XXI, Madrid. 1987.

LIGUORI, G.; VOZA, P. (orgs.). Dicionário Gramsciano (1926-1937). 1. Ed. São Paulo: Boitempo. 2017.

LOSEKANN, C. Mobilização do direito como repertório de ação coletiva e crítica institucional no campo ambiental brasileiro. Dados. Vol. 56, n. 2. 2013. Pp. 311-349.

MADEIRA, R. M.;TAROUCO, G. da S. Esquerda e Direita no Brasil: uma análise conceitual. Revista Pós Ciências Sociais, vol. 8, n. 15, jan/jun. 2011. Pp. 171-186.

Partidos, programas e o debate sobre esquerda e direita no Brasil. Revista de Sociologia e Política, vol. 21, n. 45. Mar 2013. Pp. 149-165.

MALINI, F. et al. \#Vem Pra Rua: narrativas da revolta brasileira. In: Congresso da Associação Latino-Americana de Investigadores da Comunicação. 7, 2014. Lima. Anais. Lima: Alaica, 2014. 
MENDONÇA, D. de. A teoria da hegemonia de Ernesto Laclau e a análise política

brasileira. Revista Ciências Sociais Unisinos. Vol. 43, n. 3. Set/dez 2007. Pp. 249-258.

NOBRE, M. Choque de Democracia: razões da revolta. São Paulo. Companhia das Letras. 2013.

ORTELLADO, P. et al. Vinte Centavos: a luta contra o aumento. São Paulo. Veneta. 2013.

SCHEEFER, F. Esquerda e direita: velhos e novos temas. $38^{\circ}$ Encontro Anual da Anpocs. Caxumbu, MG.

SCHERER-WARREN, I. Manifestações de rua no Brasil 2013: encontros e desencontros na política. Cadernos CRH. Salvador. Vol. 27, n.71. Mai/Ago 2014. Pp. 417 - 429.

SILVA, M. K. \#Vemprarua: o ciclo de protestos de 2013 como expressão de um novo padrão de mobilização contestatória? In: CATTANI, A. D. (org.). \#Protestos: análises das Ciências Sociais. Porto Alegre. Tomo, 2014.

SINGER, A. Brasil, junho de 2013: classes e ideologias cruzadas. Novos Estudos Cebrap. N. 97. Nov/2013. Pp. 23-40.

Esquerda e direita no eleitorado brasileiro: a identificação ideológica nas disputas presidenciais de 1989 e 1994. São Paulo: Edusp. 2000.

SZWAKO, J.; DOWBOR, M. Respeitável Público: Performance e organização dos movimentos antes dos protestos de 2013. Novos Estudos Cebrap, n. 97, 2013. Pp. 43-55.

TATAGIBA, L. 1984, 1992 e 2013: sobre ciclos de protestos e democracia no Brasil. Política e Sociedade. Vol. 13, n. 28. 2014. Pp. 35-62.

Data de recebimento: 10/10/2017

Data de aceite: 03/09/2019

\section{Sobre o autor:}

José Carlos Martines Belieiro Júnior possui graduação em Ciências Sociais pela Universidade Estadual Paulista Júlio de Mesquita Filho (1996), mestrado em Ciência Política pela Universidade de São Paulo (2001) e doutorado em Sociologia pela Universidade Federal do Paraná (2009). Atualmente é professor no departamento de Ciências Sociais da Universidade Federal de Santa Maria. Tem experiência na área de Sociologia e Ciência Política, com ênfase em Sociologia Econômica e Política Brasileira Contemporânea, atuando principalmente nos seguintes temas: governo lula, política e economia, governo FHC, ciência política e capitalismo brasileiro. Endereço Eletrônico: jcmbjunior@yahoo.com.br

Ezer Azael Moreira possui graduação em Ciências Sociais pela UFSM (2015) e é Mestre em Ciências Sociais pela UFSM (2017). Endereço Eletrônico: eser-lopes@ hotmail.com 